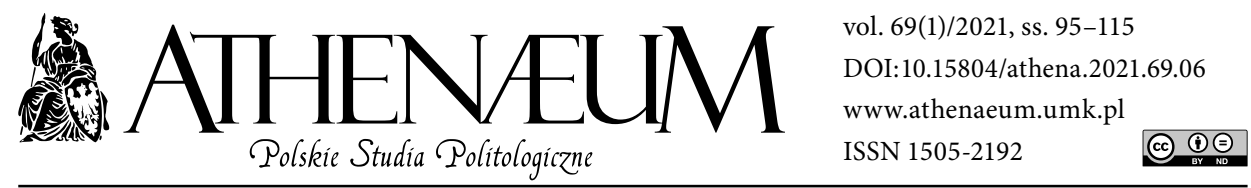

\title{
OD „KULTURY WOJNY" DO „WOJNY KULTUR”? ROZWAŻANIA O NATURZE WOJNY W XXI WIEKU
}

\author{
FROM "CULTURE OF WAR" TO "WAR OF CULTURES"? \\ REFLECTIONS ON THE NATURE OF WAR \\ IN THE 21ST CENTURY
}

Jacek Reginia-Zacharski*

\begin{abstract}
ABSTRAKT
Wojna jako ekstremalne zjawisko o naturze społecznej przez stulecia charakteryzowała się swoistą hermetycznością wobec niemilitarnych domen rzeczywistości. Zarówno w wymiarze etycznym, politycznym, prawnym, obyczajowości, a nawet języka, wojskowość i wojskowi tworzyli ekskluzywną (sub)kulturę. Wpisywały się te procesy w „triadę” Carla von Clauzewitza, który właśnie „armię” wskazywał jako wyodrębniony filar wojny. Pozostając elementem struktury państw, armie pogłębiały swoją specyfikę kulturową i pewną odrębność. Jak wskazuje część badaczy, niejednokrotnie to właściwa organizacja wojskowości w państwie i działania na rzecz wzmocnienia jego potencjału wojennego narzucały szereg rozwiązań ustrojowych, prawnych i finansowych, stając się agregatem ewolucji systemów politycznych. W pierwszej połowie XX wieku doszło do głębokich przewartościowań $\mathrm{w}$ dziedzinie relacji między sferą militarną i państwową, które po
\end{abstract}

War, as an extreme social phenomenon, for centuries was characterized by a kind of mysterious nature towards non-military domains of reality. In the ethical, political, legal, moral and even linguistic dimensions, the armies and soldiers created an exclusive (sub)culture. These processes were part of Carl von Clausewitz's 'triad', which indicated the 'army' as a separate pillar of war. While remaining an element of the structure of states, the armies deepened their cultural specificity and a certain distinctiveness. As some researchers point out, in many cases the proper organization of the military in the state and actions to strengthen its military potential imposed several systemic, legal and financial solutions, becoming an aggregate of the evolution of political systems. In the first half of the twentieth century, there was a profound re-evaluation of the relationship between the military and the state spheres. After 1945 it led to a shift of the "centre of

* Uniwersytet Łódzki, Wydział Studiów Międzynarodowych i Politologicznych. 
1945 roku doprowadziły do przesunięcia „punktu ciężkości” wojny w stronę bieguna społecznego. Konsekwencją była dość szczególna „demokratyzacja” wojskowości i postępujące rozszczelnienie dotychczasowych granic. Towarzyszyły temu procesy zmiany $\mathrm{w}$ postrzeganiu i prowadzeniu wojny. Celem stawały się w coraz większym stopniu społeczeństwa, a wobec totalizacji wojny - tradycyjny podział na domeny cywilną i wojskową uległ ostatecznemu zatarciu. Współczesna wojna zatem obliczona jest przede wszystkim na niszczenie społeczeństw, ich fundamentów oraz podstaw trwania i rozwoju. Na znaczeniu zyskują niekinetyczne i hybrydowe metody działań koercyjnych i przyporządkowane im środki. Pogłębieniu tych tendencji sprzyja rozwój kolejnego „teatru działań wojennych” - domeny psychologiczno-informacyjnej.

Słowa kluczowe: wojna; konflikty zbrojne; społeczeństwo; polityka; kultura gravity" of war closer to the social pole. The consequence was a specific 'democratization' of the military domain and the progressive unsealing of the existing borders between civil and military. It was accompanied by processes of changes in the perception and conduct of war. Societies became more and more a target, and in the face of the totalization of war, the traditional division into civil and military domains was finally blurred. Modern war, therefore, is calculated primarily to destroy societies and the foundations of their existence and development. Non-kinetic and hybrid methods of coercive actions and the means assigned to them are gaining in importance. The deepening of these tendencies is fostered by developing another "theatre of warfare" - the psychological and informational domain.

Keywords: war; armed conflicts; society; politics; culture

\section{WPROWADZENIE}

Wojna od tysiącleci była stałym i obecnym elementem interakcji między państwami i innymi podmiotami politycznymi (Reginia-Zacharski, 2014). Mimo istotnych różnic w charakterach poszczególnych wojen, pozostaje prawdopodobnie najbardziej niszczycielską formą ludzkiego zachowania. Podczas wojen giną ludzie, niszczone są zasoby, spowalnia lub zahamowaniu ulega rozwój gospodarczy, na lata degradowane jest środowisko, choroby zakaźne rozszerzają się w sposób eksplozywny. W dziedzinie konstruktów społecznych konflikty zbrojne wiążą się z monopolizacją życia przez instytucje państwa (można mówić o totalizacji władzy), społeczeństwa i wspólnoty podlegają głębokiej militaryzacji, kultury i hierarchie wartości doznają swoistego „przebiegunowania” (Bull, 2012). Wojna niszczy rodziny i odciska traumatyczne piętno w jednostkach ludzkich. Same przygotowania do wojny (zarówno agresywnej, jak obronnej) absorbują istotne zasoby, nie pozwalając na podejmowanie konstruktywnych i twórczych działań społecznych, co może prowadzić do wzrostu napięć wewnętrznych i erozji bezpieczeństwa. Można to ujmować w kategoriach swoistego „dylematu bezpieczeństwa" (Glaser, 1997; Snyder, Jervis, 1999; Posen, 1993). 
Wojna ma również głęboki wpływ na ewolucję światowej polityki i zachowania państw. W dziejach ludzkości to właśnie konflikty zbrojne stanowiły jeden $\mathrm{z}$ podstawowych mechanizmów generujących zmiany w systemie światowym, przewartościowania w modelach dystrybucji potęgi oraz gospodarki światowej. Wojny wreszcie wywarły głęboki wpływ na struktury instytucjonalne i kultury polityczne państw, co więcej, odgrywały kluczową rolę w narodzinach i upadku aktorów międzynarodowej gry. Niestety nie sposób zrozumieć współczesności bez studiowania wojen (rozumianych jako zjawiska polityczne) z przeszłości. Wiele słuszności jest w stwierdzeniu „Wojny tworzą państwa, a państwa tworzą wojny" (Tilly, 1975).

Refleksja nad relacją między fenomenem wojny a kulturą (w szczególności polityczną) obecna była w filozofii i nauce właściwie od zawsze (Platon, 1994). Oprócz funkcji konstytuującej na zasadach sprzężenia zwrotnego relację między wojną i wojskowością a kulturą wspólnoty, rozumianą jako swoiste uzasadnienie dla przyjętego modelu organizacyjnego; wojna niewątpliwie generowała pewne typy „kultur branżowych” z wyraźną dominacją zawodów związanych z wojskowością. Można przyjąć, że „ludzie wojny” niemal w każdym społeczeństwie wytwarzali raczej elitarną i ekskluzywną formację subkulturową. Niektóre koncepcje szły nawet dalej, uznając kulturę za pierwotną w stosunku do wojny. John Keegan przekonuje o wadze czynników kulturowych, co prowadzi go do twierdzenia, że wojna zawsze stanowiła, stanowi i stanowić będzie ekspresję kultury (Keegan, 2000; Keegan, 1994; Keegan, 1998). W takim ujęciu aktywność militarna, będąc swoistym rytuałem, pozbawiona zostaje „polityczności” w sferze motywacji, przebiegu oraz celów/efektów. Konsekwencją mogą być daleko posunięte ograniczenia analityczne i eksplanacyjne konfliktów zbrojnych. Już to przemawia za odrzuceniem czystej postaci takiej interpretacji wojen, choć aspekt kulturowy nie powinien być pomijany. Ponadto, w świetle optyki Keegana nie do obrony byłaby teza o powtarzalności i podobieństwie wojen toczonych w obrębie (lub na styku) tych samych kultur. Oczywiście można tłumaczyć, iż „nie ma dwóch takich samych wojen”, czy to, że „każda epoka ma swoje wojny” zmianami kulturowymi, jednak w świetle hipotezy o znacznie większym tempie zmian w charakterze wojen niż zmian kulturowych, takie rozumowanie również nie wytrzymuje krytyki.

Warto odnotować również trzy generalizujące „paradygmaty”, które zaproponował Anatol Rapaport, pisząc o podejściach do wojny: politycznym, eschatologicznym i katastroficznym (Rapoport, 1968). Spośród tych czterech kardynalnych podejść badawczych autor niniejszego artykułu zdecydowanie opowiada się za 
traktowaniem wojny jako fenomenu politycznego. Zyskuje on niewątpliwie na „badalności”, ponadto na zasadności zyskuje zastosowanie narzędzia diagnostycznego w postaci dynamicznego modelu opartego na „triadzie Clausewitza”.

\section{TRYNITARNY MODEL WOJNY - UJĘCIE DYNAMICZNE}

Wokół głośnej „triady Clausewitza” narosło wiele interpretacji i nieporozumień. Z reguły traktowana jest ona jako statyczny opis „modelu” wojny, w którym poszczególne elementy są ujmowane i analizowane rozdzielnie. Część interpretacji zawiera wniosek postulatywny o nieprzekraczalności granic między trzema obszarami. Interesujące konsekwencje pojawiają się, gdy potraktować konstrukcję pruskiego stratega jako model dynamiczny, w którym charakter wojny determinowany jest dominacją jednego lub pary czynników.

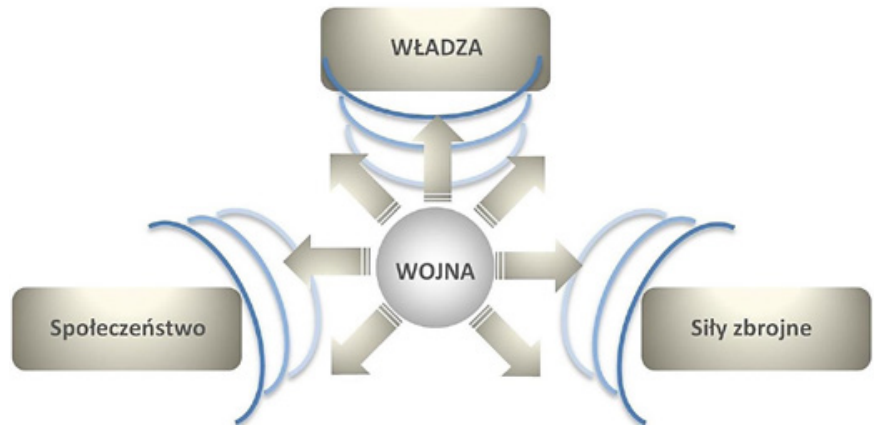

Ryc. 1. Dynamiczny model wojny/konfliktu zbrojnego

Źródło: Opracowanie własne.

Należy odnotować, że poszczególnym biegunom przypisywane są różne cechy motywujące oraz akceleratory (agregaty) zachowań. Polityczny biegun „władzy” identyfikowany jest jako najsilniej zakorzeniony w domenie racjonalnej. Charakteryzuje się ona pewną przewidywalnością i kontrolą, skłonnością do minimalizacji ryzyka, zdolnością do negocjacji (Paret, 2007; Heuser, 2008) itd. Czynnik „społeczny” jest przede wszystkim umiejscowiony w domenie emocji i instynktów. Ta, z natury swojej, jest słabo kontrolowalna, mało przewidywalna i pozbawiona racjonalności. Ostatni element triady - siły zbrojne, przynajmniej w założeniach posiadają charakter techniczny. Stanowią zatem „narzędzie” realizacji określonych (a właściwie określanych) celów politycznych. 
W klasycznym (Clausewitzowskim) podejściu do konfliktu zbrojnego wszystkie elementy pozostają ze sobą zbalansowane i rozdzielne, przy czym zdecydowanie dominującą pozycję zajmuje czynnik polityczny, czyli „władza” (Echevarria II, 2007; Echevarria II, 2010). W ten sposób wypełniony pozostaje postulat „polityczności” wojny, rozumianej jako orężne starcie o realizację celów sformułowanych przez właściwie umocowane (legitymizowane) centra polityczne. Czynnik społeczny jest nie mniej istotny, jednak powinien pozostawać w swoistej podległości wobec gron decydenckich. Stanowić ma zaplecze logistyczne, bazę rekrutacyjną oraz źródło legitymizacji „władzy” przy formułowaniu decyzji dotyczących wojny i pokoju. Pozbawiony jest natomiast podmiotowości w samym procesie decyzyjnym (Echevarria II, 2010). Właściwie można pójść dalej - jako trudna do kontrolowania duża zbiorowość, społeczeństwo (naród), nie posiada właściwie zdolności do formułowania celów i ich operacjonalizacji. Nie mniej pozostaje społeczeństwo silnym czynnikiem warunkującym samą decyzję o wejściu w konflikt zbrojny, jak również sposób jego prowadzenia (Strachan, 2006). Akceptacja i progi poparcia dla programu politycznego konfliktu (celów), obciążeń (kosztów) z nim związanych i spodziewanych efektów (zysków) powinny posiadać akceptację społeczną. Wyjaśnić takie stanowisko można, sięgając choćby po narzędzie racjonalizacji wysiłków (Crawford, 1991). Władza, która realizuje koercyjny program polityczny na zewnątrz (angażuje się w wojnę/konflikt zbrojny) przy braku akceptacji społecznej, ryzykuje konieczność działań wymuszających wewnątrz państwa (Bueno de Mesquita, Smith, Siverson, Morrow, 2003). W ten sposób istotna część sił, dysponujących zdolnością użycia przemocy, musi zostać oddelegowana do zadań wewnętrznych, osłabiając tym samym potencjał państwa w działaniach zewnętrznych (Calhoun, 2013). Należy również odnotować, że relacje władza-społeczeństwo w sytuacjach konfliktowych (zarówno na etapie konceptualizacji, jak realizacji) silnie warunkowane są cechami reżimów politycznych (Bueno de Mesquita i in., 2003). Siły zbrojne (armia) w tym przypadku pozostają narzędziem celów określonych na szczeblu politycznym, czy też w efekcie utarcia się jednolitego stanowiska władz politycznych i nastrojów społecznych. Pozostają zatem narzędziem prowadzenia polityki „... przy użyciu innych środków”, „instrumentem polityki” itd. (Clausewitz, 2006; Clausewitz, 2007; Heuser, 2008; Strachan, 2009). Podkreślić jednak trzeba, że model ten charakteryzuje się dużą statycznością i niewzruszonością.

Istotą podejścia dynamicznego jest teza o zmienności charakteru konfliktu zbrojnego (wojny) i jej „przemieszczania się” w okolice poszczególnych „biegunów”. Tym samym zmienia się ich siła oddziaływania na charakter i cechy 
prowadzonych działań. Wydaje się, że można wskazać trzy scenariusze skrajne, przy czym niezbędne jest zaznaczenie, iż między nimi swoje miejsce znajdują sytuacje „mieszane”.

Przesuwanie się ciężaru sytuacji konfliktowej w kierunku dominanty z modelu Clausewitza, czyli „bieguna” władzy, powoduje dość oczywistą demilitaryzację konfliktu, bowiem na znaczeniu wyraźnie zyskują rozwiązania dyplomatyczne/ polityczne. Dzieje się tak wobec naturalnego osłabienia roli czynnika społecznego i odwoływania się do rezerwuaru środków twardych związanych z siłami zbrojnymi. Otwarte pozostaje pytanie o skuteczność negocjacyjną decydentów politycznych w sytuacji pewnego wyalienowania środowisk politycznych od czynnika społecznego (niskie poparcie) oraz relatywnie możliwej niskiej oceny zdolności militarnych (przy słabości „bieguna” sił zbrojnych) (Slantchev, 2011). W odniesieniu do tego ostatniego elementu uzasadniona wydaje się hipoteza o skłonności do preferowania stanowisk miękkich w negocjacjach (Kagan, 2003; Lenschow, 2006; de Schoutheete, 2001).

Skrajne przesunięcie się konfliktu w stronę bieguna sił zbrojnych powoduje jego absolutną militaryzację i podporządkowanie celów politycznych celom wojskowym, aż do zupełnej marginalizacji tych pierwszych. Sensem wojny staje się samo jej trwanie, a celem wewnętrznym totalna (totalitarna?) militaryzacja społeczeństwa, które staje się „armią” bądź jej zapleczem. W tej perspektywie "pokój” postrzegany jako osiągnięcie uznawanego za optymalne rozwiązania politycznego, właściwie nie istnieje wobec praktycznej likwidacji domeny politycznej (Herwig, 2014; Redner, 2017). Clausewitz nazywał ten „rodzaj wojny” doskonała, absolutna - choć przestrzegał przed sięganiem po metodę „uzbrajania całego narodu" (Clausewitz, 2007), uznając to narzędzie za absolutnie niemożliwe do kontrolowania $\mathrm{i}$ - w istocie - pozapolityczne (Vennesson, 2011). Nieco inny wątek pozwala postawić hipotezę, iż hierarchizacja wśród decydentów w tym rodzaju konfliktu powoduje dość daleko idącą elitaryzację, co ułatwia identyfikację i zawęża krąg beneficjentów konfliktu. W sytuacji, gdy zakładany bilans zysków i strat przestaje być korzystny - jak wykazują badania Bruce'a Bueno de Mesquity - wzrasta gotowość do zakończenia konfliktu (Bueno de Mesquita i in., 2003; Bueno de Mesquita, Siverson, Woller, 1992).

Trzeci z możliwych scenariuszy brzegowych - przesunięcie konfliktu w stronę bieguna społecznego - wykazuje wiele podobieństw z modelem drugim. Społeczeństwo zostaje w całości ogarnięte konfliktem, z czego bezpośrednio wynika brak podziału na sferę cywilną i militarną. Jednak przesunięcie całości motywacji do domeny „emocji i instynktów” powoduje marginalizację lub likwidację ele- 
mentu racjonalnego. Konflikt zatem zbliża się do „doskonałości”, wobec braku możliwości identyfikowania zoperacjonalizowanych celów politycznych. Można przyjąć, że jedną z głównych motywacji w tym typie konfliktu staje się spirala akcja-reakcja, obciążona nieusuwalnym potencjałem eskalacji. Jednocześnie taki charakter konfliktu wykazuje fundamentalną różnicę w stosunku do modelu drugiego - wobec nikłego występowania pierwiastka profesjonalnego (który w przypadku dominacji „armii” wysuwa się na plan pierwszy), nieodłączną cechą konfliktu z dominantą społeczną staje się jego anarchizacja i chaotyczność. Wobec braku wyraźnych struktur i hierarchii konflikty takie wykazują naturalną dążność do swoistej atomizacji (Reginia-Zacharski, 2014), która wynika między innymi (a być może przede wszystkim) ze swoistej ekonomizacji wojny (Münkler, 2004). Częstym efektem takiego procesu jest postępująca „kryminalizacja” wojny (Reginia-Zacharski, 2014), a tym samym społeczeństw w nią zaangażowanych (Scherrer, 2003). Cechy wojny przy przyjęciu za kryterium siłę oddziaływania poszczególnych elementów „trójcy” dają się ująć w następującej zależności:

Cechy konfliktu zbrojnego w zależności od dominanty czynnika („bieguna”)

\begin{tabular}{|c|c|c|c|c|}
\hline „Biegun” dominujący & $\begin{array}{c}\text { Poziom kontroli } \\
\text { konfliktu }\end{array}$ & $\begin{array}{c}\text { Militaryzacja } \\
\text { konfliktu }\end{array}$ & $\begin{array}{c}\text { Agregat } \\
\text { eskalacji }\end{array}$ & $\begin{array}{c}\text { Poziom } \\
\text { brutalności }\end{array}$ \\
\hline Władza & Wysoki & Niska & Niski & Niski \\
\hline Siły zbrojne & Wysoki & Wysoka & Średni & Sredni \\
\hline Społeczeństwo & Niski & Narastająca & Wysoki & Wysoki \\
\hline
\end{tabular}

Źródło: Opracowanie własne.

Wskazane wcześniej „stany pośrednie” należy rozumieć jako zmienne w czasie przesunięcia na skali znaczenia poszczególnych „biegunów”. Konflikt zbrojny, jako zjawisko dynamiczne i rozciągnięte w czasie, podlega również zmianom w charakterze, natężeniu itd. Tak zresztą należy rozumieć metaforę Clausewitza (Clausewitz, 2007), porównującą wojnę do kameleona (Echevarria II, 2007). Różne czynniki towarzyszące konfliktom zbrojnym, zarówno od ich początku, jak i te, które pojawiają się w ich przebiegu (np. w związku z „tarciem”), sprawiają, że poszczególne „bieguny” zyskują na znaczeniu kosztem pozostałych (Davies, 1997; Walt, 1996). Niezależnie jednak od miejsca, które w danym momencie zajmuje w polu oddziaływania biegunów konflikt zbrojny, pozostaje on zjawiskiem ze wszech miar „politycznym”. Politykę (i „to, co polityczne”) bowiem można analizować na kilku obszarach - działalności instytucji państwowych; wzajem- 
nych stosunków władzy, wpływu i konfliktu; funkcji w systemie społecznym; procesów podejmowania decyzji oraz mechanizmów i zdolności rozwiązywania problemów (Jabłoński, 1991). Jeśli przyjąć dychotomiczne ujęcie Zbigniewa Bloka, w którym kryteriami są model stosunków społecznych i aktywności społecznej (Blok, 2009), to konflikt zbrojny (wojna) wypełnia te ramy (Czajowski, 2011), z zastrzeżeniami poczynionymi przez H. Bulla (Creveld, 2008). W rozumieniu szwedzkiej szkoły rozwiązywania konfliktów, większość ze starć daje się analizować przy zastosowaniu dwóch kryteriów motywacji - władzy i zasobu (Wallensteen, 2011; Wallensteen, 2001; Eck, 2005; Sollenberg, Melander, 2017). Uppsala Conflict Data Project (UCDP) i Sztokholmski Instytut Badań nad Pokojem (Stockholm International Peace Research Institute - SIPRI) pod pojęciem zasobu rozumieją co prawda przede wszystkim terytorium, jednak to ograniczenie wydaje się nieuzasadnione. Właściwie należałoby podkreślić, iż opanowanie jakiegokolwiek „zasobu” - materialnego bądź niematerialnego, sprowadza się do rozciągnięcia nad nim władztwa. Stąd można wywieść wniosek, że celem rywalizacji - w tym zbrojnej - jest po prostu władza/władztwo (w wymiarze materialnym i niematerialnym). Tak zwany „system westfalski” opiera się na kardynalnym postulacie, który w pewnym uproszczeniu można ujmować jako monopolizacja władztwa przez państwo. W oparciu o takie założenie można sformułować tezę, iż „rzeczywistość westfalską” charakteryzuje potencjał dwóch rodzajów konfliktów zbrojnych: państwo - państwo (ten model również występuje w układzie zbiorowym) oraz państwo - podmiot niepaństwowy. Posługując się nomenklaturą Carla Schmitta (Schmitt, 1963), można przyjąć, że ten pierwszy zbiór zjawisk stanowią „konflikty między uczestnikami regularnymi”, tę drugą zaś „konflikty między uczestnikiem regularnym i nieregularnym” (Ralph, 2010).

\section{WOJNA A KULTURA}

Jak pisano wcześniej, z pespektywy kulturowej każdy z „biegunów” w ujęciu trynitarnym kształtował swoją „subkulturę branżową", charakteryzującą się swoistą ekskluzywnością. Społeczeństwa rozwijały własne kultury, które stanowiły podstawowy budulec i spoiwo ich trwania i funkcjonowania jako fenomenów politycznych. Można uznać, że właśnie szeroko rozumiana kultura stanowiła (i stanowi) główny budulec wspólnotowości, której wyrazem stawały się społeczności, społeczeństwa i ich polityczne emanacje - w postaci wysokiej - państwa. Postawić można zatem hipotezę, że kultury pozostają jednym z podstawowych 
elementów konstrukcyjnych i konstytutywnym państw jako głównych uczestników stosunków międzynarodowych. Warto przy tym zauważyć, że w domenie społecznej część kultur przeszło ewolucję od ekskluzywności do inkluzyjności. Jedną z postaci tego fenomenu stało się „,społeczeństwo otwarte” i jego aksjologiczne podstawy (Beck, 2002).

W odniesieniu do dwóch pozostałych domen (biegunów) należy podkreślić, iż pozostawały one $\mathrm{w}$ wysokim stopniu ekskluzywne, także $\mathrm{w}$ wymiarze kulturowym. Biegun „władzy” (polityczny) w zależności od panującego systemu, pozostawał bardziej lub mniej wyabstrahowany z domeny społecznej. Zjawisko to najsilniej występowało w systemach monarchicznych, choć warto podkreślić, iż właściwie we wszystkich koncepcjach (Pareto, 2009; Bagehot, 2016; Sztumski, 2007) i typologiach (Weber, 2011; Weber, 2002; Augustyniak, 2010; Krasnodębski, 1999) legitymizacji władzy (Zieliński, 2001; Żyro, 2004) widoczna jest ekskluzywność auctoritas w stosunku do społeczeństwa. W takiej sytuacji w naturalny sposób wykształciły się tendencje do pewnej elitarności i ekskluzywności kulturowej sfery politycznej, zarówno w wymiarze głębokim, jak też powierzchownym. Ta pierwsza domena może być postrzegana w kategoriach różnych elementów systemowej „kultury politycznej” (Giddens, 2003; Zybertowicz, 1995), druga zaś w pewnych rytuałach związanych z zachowaniami, zwyczajami, a nawet strojem (Kuper, 1973). A jednak współczesność przekonuje o tym, że (sub)kultura polityczna wykazuje tendencje do zacierania wyrazistości rozgraniczenia. Niezmienną praktyką polityków stało się deklarowanie przez nich braku tej granicy (zarówno w warstwie werbalnej, wizualnej i innych), co prowadzi niekiedy do kuriozalnych sytuacji, w których politycy składają oświadczenia, że „nie zajmują się polityką" (Raco, 2015). Oczywiście można zakładać, że wiele w tym taktyki odwołującej się do mechanizmów dezinformacyjnych, jednak ich skuteczność przekonuje o istnieniu społecznego zapotrzebowania na sięganie po takie środki (Tesfahuney, Ek, 2015).

Podobne uwagi można odnieść do stricte militarnego obszaru Clausewitzowskiej „triady”. Kalevi J. Holsti stawia tezę, iż okres wyraźnego wyodrębnienia kultury wojskowej w Europie w wymiarach głębokich i płytkich przypada na czasy po zawarciu pokoju westfalskiego, czyli po 1648 roku (Holsti, 1992; Holsti, 2004). Wiązać się to miało z postulatem ograniczania destrukcyjnego oddziaływania działań wojennych do obszarów militarnych, ograniczając tym samym niszczenie pozostałych obszarów, które miały stać się łupem zwycięzcy. Holsti wskazuje na procesy, które doprowadziły do wyłonienia stałych armii, wyraźnie oddzielonych od reszty społeczeństwa zarówno w wymiarze mental- 
nym (kodeksy zachowań, prawo wojskowe itd.), jak też wizualnym (mundury) (Holsti, 2004). Procesy „wydzielania” kultury militarnej nie zostały odwrócone nawet w czasach pojawienia się armii masowych - zmienił się nieco charakter zjawiska (Holsti, 1992). Odrębnego zdania jest Michel Howard, który wskazuje, iż taka odrębność towarzyszyła Europejczykom od zawsze (Howard, 2001). Takie stanowisko prezentuje również Martin van Creveld (Creveld, 2008). Wskazuje on na zamkniętość „kultury wojny”, ale jednocześnie jej promieniowanie do pozostałych domen triady. Nie mniej jednak, właśnie w dziedzinie kultury wojskowość przez wieki pozostawała agregatem wzorców zachowań i swoistego rytuału (Neiberg, 2004). O istocie kultury wojny w dziejach społeczeństw oraz zasadności badań przekonywał van Creveld, pisząc: „W wielu społeczeństwach (...) kultura militarna cieszyła się niezwykle wysokim statusem. Na przykład (...) XVI-wieczny francuski rycerz Brantôme nazwał rycerskość 'religią honoru' i twierdził, że powinna mieć ona pierwszeństwo przed wszystkimi innymi formami kultury. Żadne imperium, cywilizacja, ludzie i religia nigdy nie osiągnęły wielkości, bez (...) ‘biznesu bicia’. Bardzo często najbardziej wpływowe idee, religie, narody, cywilizacje i imperia są tworami tych, którzy posiadali najwięcej armat i, wykorzystując je, pokonywali innych. (...) Chociaż 'pięknoduchy’ mogą nie lubić tego faktu, wojna i jej kultura stanowią integralny element ludzkiej historii (...) i tak prawdopodobnie będzie w przyszłości. (...) Aby zrozumieć te zjawiska, muszą one być badane nie mniej dokładnie i uważnie niż jakakolwiek inna część ludzkiej aktywności. (...) Prawdą jest, że podobnie jak w przypadku każdej kultury, wiele z tego, co otacza wojnę, jest nieracjonalne i nie przystaje do jakichkolwiek wzorców utylitarnych. Jednak fakt ten nie zmniejsza znaczenia $\mathrm{i}$ istotności zjawiska kulturowego. Jednym $\mathrm{z}$ istotnych uwarunkowań jest fakt, że pozbawiona swojej ‘bezużytecznej’ kultury wojna ulegnie degeneracji w zwykłą orgię przemocy, nie regulowaną przez żadną organizację, bez określonego celu i sensu. Jest oczywiste, że historia była świadkiem wielu takich orgii. (...) To prowadzi do prawdziwego powodu, dla którego kultura wojny ma znaczenie odgrywa kluczową rolę w przezwyciężaniu naturalnej skłonności ludzi do unikania niebezpieczeństwa, a jednocześnie przygotowuje ich do złożenia najwyższej ofiary, jeśli będzie to konieczne" (Creveld, 2008: xii-xiii).

$\mathrm{W}$ innym miejscu izraelski badacz zwraca uwagę na fenomen zmiany w tym wymiarze, który obserwowalny jest we współczesnym świecie: „(...) w wielu współczesnych państwach, które same się określają mianem 'zaawansowanych', kultura wojny nie cieszy się (...) estymą. (...) W najlepszym razie ocenia się ją jako osobliwą pozostałość z mniej racjonalnej, mniej utylitarnej i mniej huma- 
nitarnej przeszłości. W najgorszym jest ona negowana, odrzucana, ignorowana, wyśmiewana lub potępiana jako dziecinne <<podżeganie do wojny〉>" (Creveld, 2008: xiv).

Można przyjąć, że relacja między „kulturą wojny” a kulturą „,ogólnospołeczną” układała się z reguły falująco. Po okresach wysokiej popularności tej pierwszej i wyraźnie zauważalnego wpływu (Holsti, 2004), a nawet zakorzeniania się na tę drugą, przychodziły czasy odrzucenia i pogardy. Długości poszczególnych interwałów oczywiście nie były równe, co więcej - trudne do uchwycenia są punkty zwrotne, niemniej jednak powyżej wskazaną tezę można dość łatwo obronić (Ross, 2015; Fiala, 2010). Należy jednak z całą mocą podkreślić rozdzielność tych dwóch źródeł i obszarów kultury, które mimo przenikania i wzajemnych wpływów posiadały wyraźną skłonność do ekskluzywności i pewnej elitarności. W szczególności uwaga ta dotyczy kultury militarnej. Wydaje się, że w ostatnich dziesięcioleciach dostrzegalny jest nowy, wcześniej raczej nieobserwowany trend. Zdecydowanie silniejszy staje wpływ kultury cywilnej na ,środowisko wojskowe”, podczas gdy w przeszłości wektor relacji wzajemnych skierowany był raczej odwrotnie. Procesy te są przede wszystkim widoczne w siłach zbrojnych państw „zaawansowanych”, by użyć terminologii Van Crevelda. Można wskazać wiele przyczyn tego zjawiska - realizacja paradygmatu cywilnej kontroli nad wojskiem, przenoszenie do sił zbrojnych reżimu „ochrony praw człowieka”, przemiany w podejściu do składu osobowego sił zbrojnych (pojawienie się i stały wzrost liczby kobiet w armiach), outsourcing (sięganie po podmioty zewnętrzne dla obsługi sił zbrojnych) itd. Nie mniej istotne stają się jednak przede wszystkim wymogi współczesnego nowoczesnego pola walki, na którym wzrasta zapotrzebowanie na umiejętności (Hoffman, 2017-2018) daleko wykraczające poza „klasycznie” pojmowaną sferę militarną (Piotrowski, 2015). Ta rzeczywistość jest ilustrowana choćby koncepcjami „wojen hybrydowych" (Gruszczak, 2011; Reginia-Zacharski, 2014) czy konfliktów nielinearnych (Lawson, 2014). Zaznacza się to również w szeroko rozumianej sferze cywilizacyjnej. O ile przez większą część dziejów ludzkości wojna pozostawała motorem inwencyjności, a wynalazki opracowywane na potrzeby zwiększenia potencjału militarnego po pewnym czasie trafiały do sfery cywilnej, obecnie obserwować można zmianę kierunku przepływu. Wiele technologii cywilnych trafia do obszaru zainteresowania wojskowych i jest (po modyfikacjach lub bez nich) adaptowana do potrzeb sił zbrojnych (Roland, 2016). Niejednokrotnie powoduje to głębokie przewartościowania w charakterze służby wojskowej - coraz większa liczba żołnierzy różni się od pracowników korporacji cywilnych tym, że w pracy pojawia się w mundurach (Szafranski, 1997). Na zmieniający się charakter 
współczesnej wojny zwracał w swoich esejach Michael Walzer (Walzer, 2010). Cywilizacyjne zmiany nie ominęły również sfer dotyczących statusu członków sił zbrojnych (Gilbert, 2003; Dörmann, 2003; Dinstein, 1989; Kwiecień, 2009), ich etyki (McMahan, 2004) i etosu, warstwy zwyczajowej, rytuałów i innych pół, składających się na kulturę wojny (Creveld, 2008).

Podsumowując ten fragment rozważań, można przyjąć, że hybrydowość (hybrydyzacja?) nie ominęła tradycyjnego styku, ale i rozdziału między kulturami poszczególnych „biegunów” z triady Clausewitza. Doszło do dość specyficznego amalgamatu fenomenów kulturowych, a właściwie wykształcenia hybrydowej kultury o dość labilnej zawartości, z silnie zaznaczoną dominantą i wpływem kultury generowanej przez „biegun” społeczny.

\section{„WOJNA KULTUR" (?)}

Jedną z tez sformułowanych przez Kalevi'ego J. Holstiego w pracy The State, War, and the State of War (Holsti, 2004) jest stwierdzenie, iż w wyniku traumy, jaka dla państw i społeczeństw Europy Zachodniej stanowiła wojna trzydziestoletnia, pojawiła się tendencja do wyraźnego wydzielenia wojny z innych sfer aktywności człowieka. Takie stanowisko oparte zostało na przekonaniu, iż zniszczenia wojenne i klęski towarzyszące działaniom zbrojnym były tak dotkliwe (Wilson, 2009; Roberts, 1998; Wilson, 2010), że bilans dla żadnej z walczących stron nie wypadł zadowalająco. Wobec tego po 1648 roku pojawiło się zapotrzebowanie na swoiste skanalizowanie wojny, która miała być (oczywiście w modelu idealnym) pojedynkiem, rozgrywającym się na zdefiniowanym i ograniczonym obszarze. Dotyczyło to zarówno przestrzeni, czasu, jak i zasięgu w wymiarze ludzkim. Ostatecznie można zgodzić się z określeniem tego procesu w kategoriach dążeń do „ograniczenia/limitowania” wojny (Holsti, 2004). Według wielu badaczy stan taki utrzymywał się do pierwszej wojny światowej, choć zdarzały się okresy zachwiania - przede wszystkim czas wojen napoleońskich, $\mathrm{z}$ francuską koncepcją levée en masse - narodu pod bronią, czy równoległy, choć niezrealizowany w pełni, pruski koncept powołania pod broń narodu, jako odpowiedź na francuskie sukcesy (Hagemann, 2015). Na marginesie warto zauważyć, że właśnie takie rozwiązania były tym, przed czym przestrzegał von Clausewitz, uznając je za zbliżanie się do kryteriów wojny doskonałej/absolutnej (Clausewitz, 2006). O ile w wieku XIX umasowienie wojny i jej swoista „demokratyzacja” manifestowały się jako pewne „przebłyski” innej rzeczywi- 
stości polityczno-społecznej, to następne stulecie zaznaczyło się narastającym procesem totalizacji zjawisk konfliktowych (Bell, 2007; Black, 2010). Właściwie już wojna secesyjna w Stanach Zjednoczonych uznawana jest za pierwszą wojną totalną, w Europie była nią Wielka Wojna (najpóźniej od drugiego roku jej trwania). Istotą „totalności” stało się zaangażowanie wszystkich mocy, pozostających w dyspozycji państw na rzecz wysiłku wojennego. Stąd rozdział na to, co wojskowe i cywilne tracił rację bytu. Wygrywał wojnę ten, kto dłużej był w stanie ją prowadzić, tak w wymiarze surowcowym, jak też mocy wytwórczych i zdolności społeczeństw (narodów) do ponoszenia jej ciężarów. Społeczeństwo stało się jednym z celów działań wojennych. Druga wojna światowa ukazała ten „nowy” charakter wojny z przerażającą wyrazistością. Jak twierdzi K.J. Holsti, o ile jeszcze w czasach pierwszej wojny światowej cywile stanowili około $20 \%$ ogółu ofiar (pozostałe $80 \%$ stanowili żołnierze), to na następnych konfliktach te proporcje przeszły głębokie przemiany. Druga wojna światowa na niektórych frontach zaznaczyła się zupełnym odwróceniem proporcji, a wiele wojen po 1945 roku potwierdza utrzymywanie się (a nawet eskalację) tej tendencji (Holsti, 2004). Pojawienie się broni jądrowej (1945 r.), a przede wszystkim jej „demonopolizacja” (Josephson, 2005; Little, 2007) po 1949 roku spowodowały, że wojna między potęgami, dysponującymi potencjałem nuklearnym, przeniosła się do kategorii obciążonych ryzykiem nie do akceptacji (Schelling, 1966; Edwards, 1986). Zimnowojenny świat znajdujący się w okowach logiki „obustronnie gwarantowanego zniszczenia”, mimo niebywale wysokiego napięcia w relacjach międzynarodowych, naznaczony był tendencją do szukania pól rywalizacji w obszarach innych niż bezpośrednie militarne starcie głównych potęg (Cimbala, 1995). Oprócz tzw. wojen zastępczych (Mumford, 2013) sięgano po niekinetyczne metody destrukcyjnego oddziaływania na społeczeństwa definiowane jako wrogie. Po zakończeniu „zimnej wojny” na wielu obszarach, oddalonych od „systemowego rdzenia”, wojny wybuchły z siłą długo tłumionych żywiołów. Wśród aktorów dysponujących potężnymi tradycyjnymi środkami niszczenia, po krótkotrwałej la belle époque lat 90. XX wieku, rywalizacja przy użyciu narzędzi niekinetycznych weszła w nową fazę. Jej niszczycielskiej sile sprzyja rozwój „masowych” narzędzi komunikacyjnych (Rastorguyev, 1999; Thomas, 2004; Shemayev, 2007, Creveld 2014). W dzisiejszym świecie nie ma już właściwie środowisk (naukowych, politycznych i innych), które podważałyby to, że „wojna informacyjna” jest stałym elementem rzeczywistości społeczno-politycznej (Giles, 2016; Information Warfare, 1996; Poindexter, 2018; Clark, 2017; Denning, 2006; Daniluk, 2014). 
Ten fenomen - przynajmniej w odniesieniu do części świata - jest stosunkowo łatwy do wyjaśnienia. Jest bowiem efektem „zderzenia” dwóch opisanych wcześniej tendencji - totalizacji wojny oraz osiągnięcia tak wysokiego potencjału zniszczenia przez „państwa zaangażowane”, że ryzyko podjęcia działań kinetycznych i wieloobszarowe koszty wojny przeniosły się do obszaru nieakceptowalnego. Efektem działań niekinetycznych (realizowanych w domenie informacyjnej) ma być rozwiązanie zarysowanego powyżej paradoksu - realizacja uderzeń o charakterze totalnym, przy obniżeniu ryzyka i kosztów działań (Schelling, 1980). Wspomniana domena informacyjna oferuje podmiotom agresywnym szereg korzyści. W istniejącym prawie międzynarodowym większość z dostępnych opcji pozostaje klasyfikowana „poniżej progu wojny”. Zmasowane ataki niekinetyczne raczej nie mieszczą się w retoryce wynikającej z Karty Narodów Zjednoczonych i trudno je uznać za przejawy „...zagrożenia lub naruszenia pokoju bądź aktu agresji” (KNZ, art. 39; Kranz, 2009). Trudno też wyobrazić sobie sytuację, w której Rada Bezpieczeństwa podejmuje stosowną rezolucję (KNZ art. 41 i 42) w odniesieniu do działań z domeny niekinetycznej. Osobną kwestię stanowią zagadnienia dotyczące możliwości stwierdzenia „aktu agresji” i działań napastniczych, które nawet $\mathrm{w}$ odniesieniu do działań $\mathrm{z}$ domeny kinetycznej pozostają kategorią nieostrą (Kranz, 2009). Można zatem przyjąć, że teza o potencjale rozwiązania paradoksu totalności wojny i akceptowalnych kosztów/ryzyka (Cimbala, 1991) w domenie działań niekinetycznych jest prawdziwa. Sięganie zatem po narzędzia niekinetyczne w środowisku, gdzie rywalizacja (jako naturalna cecha podmiotów $\mathrm{w}$ stosunkach międzynarodowych) podlega $\mathrm{z}$ jednej strony tendencji do totalizacji, $\mathrm{z}$ drugiej w środowisku $\mathrm{z}$ wysoko definiowanymi kosztami użycia przemocy zbrojnej (Wusten, 2005), staje się racjonalnym wyborem (Fearon, 1995; Walt, 2000).

Jak słusznie zauważają Jack S. Levy i William R. Thompson, „...Strategiczna (...) siła państwa może zostać zakłócona przez psychologiczne uwarunkowania, biurokratyczne utrudnienia w przetwarzaniu informacji, zniekształcenia kulturowe i inne czynniki wewnętrzne" (Levy, Thompson, 2010: 69). Na poziomie badania głębokich przyczyn (Garnett, 2009) konfliktów zbrojnych istotne może być śledzenie różnic kulturowych, które mogą być powodem bądź pretekstem dla decyzji o sięgnięciu po przemoc zbrojną (Snyder, 1991). A jednak, uwzględniając wcześniej podniesione uwagi, warto przypomnieć, że w warunkach totalizacji wojny celem staje się społeczeństw/naród/wspólnota. Przy wykazanej wcześniej zasadności postulatu sięgania po środki niekinetyczne rodzi się pytanie o precyzyjne cele uderzeń. Wydaje się, że domena kultury, rozumianej 
jako rzeczywiste spoiwo (fundament) wspólnot, staje się naturalnym „teatrem wojny informacyjnej". Uwaga ta dotyczy z pewnością poziomów strategicznego i operacyjnego.

Analizując fenomen niekinetycznego uderzania w domenę kultury, można sięgnąć do terminologii odwołującej się do koncepcji siły, zaproponowanej przez Josepha Nye jr. Można przyjąć, że siłę destrukcyjną również można podzielić na subdomeny - „twardą” (hard) siłę destrukcyjną (hard distructive power - HDP) i „miękką" siłę destrukcyjną (soft destructive power - SDP). Korespondują one - do pewnego stopnia - z użytą wcześniej klasyfikacją działań kinetycznych i niekinetycznych.

\begin{tabular}{|c|c|c|}
\hline $\begin{array}{l}\text { hard distructi- } \\
\text { ve power } \\
\quad \text { - HDP }\end{array}$ & soft destructive power - SDP & \\
\hline $\begin{array}{l}\text { Domena } \\
\text { działań } \\
\text { kinetycznych } \\
\text { (DDK) }\end{array}$ & $\begin{array}{l}\text { Fizyczne niszczenie celów } \\
\text { materialnych, w szczególności } \\
\text { w infrastrukturze krytycznej } \\
\text { POZIOM TAKTYCZNY }\end{array}$ & $\begin{array}{c}\text { Pozbawianie możliwości działań w zakresie obsługi } \\
\text { materialnych elementów obrony i ochrony, poprzez } \\
\text { prowokowanie blokad, np. jednostek wojskowych, } \\
\text { osłabianie morale sił zbrojnych i służb, niszczenie } \\
\text { zaufania dla administracji państwa, prowokowanie } \\
\text { nieuzasadnionych aktów „nieposłuszeństwa } \\
\text { obywatelskiego” itd. } \\
\text { POZIOM TAKTYCZNY/POZIOM } \\
\text { OPERACYJNY }\end{array}$ \\
\hline $\begin{array}{l}\text { Domena } \\
\text { działań nieki- } \\
\text { netycznych } \\
\text { (DDNK) }\end{array}$ & $\begin{array}{l}\text { Przechwytywanie informacji } \\
\text { przeciwnika, dezinformacja woj- } \\
\text { skowa. Niszczenie i zakłócanie } \\
\text { działania na poziomie infra- } \\
\text { struktury: procesów decyzyj- } \\
\text { nych, systemów informacyjnych, } \\
\text { analitycznych itd. } \\
\text { POZIOM OPERACYJNY }\end{array}$ & $\begin{array}{c}\text { Niszczenie i osłabianie więzi społecznych, trady- } \\
\text { cyjnych systemów wartości, modeli społecznych; } \\
\text { fragmentaryzacja społeczeństwa, wywoływanie } \\
\text { wrogości wewnątrz wspólnoty itd. }\end{array}$ \\
\hline
\end{tabular}

$\mathrm{Z}$ powyższego zestawienia można wnosić, że narzędzia $\mathrm{z}$ arsenału soft destructive power dają możliwość działania na wszystkich dostępnych poziomach uderzania w przeciwnika. Bezpośrednio kultury, stanowiącej podstawowy agregat więzi społecznych, dotyczy obszar definiowany jako przecięcie SDP i domeny działań niekinetycznych. Odnosząc się do obserwacji poczynionych przez Nye’a, należy podkreślić, że charakteryzuje się on stosunkowo czasochłonną i mało doraźną perspektywą przygotowań oraz realizacji, jednak jego 
efekty są zdecydowanie trwalsze i głębsze niż w przypadku sięgania po HDP. Skrzyżowanie narzędzi DDK i SDP właściwie odpowiada swoją specyfiką obu domenom HDP. Zresztą wszystkie te trzy pola macierzy ogniskują się na poziomach taktycznym i operacyjnym. Jedynie SDP/DDNK funkcjonuje w wymiarze strategicznym.

\section{KONKLUZJE}

Jak wykazano wyżej, w środowisku wojny od początku XX wieku zachodzą głębokie przewartościowania. Nabrały one wyraźnego przyspieszenia, jak również określonego ukierunkowania po zakończeniu zimnej wojny. Celem działań stały się w stopniu decydującym społeczeństwa, rozumiane jako fenomeny kulturowe. Odróżnia to sytuację obecną od „tradycyjnie” postrzeganych jako „westfalskie” i „Clausewitzowskie” celów w postaci niszczenia sił zbrojnych. Jedną z podstawowych przesłanek dla takiego stanu rzeczy stanowi niewątpliwie totalizacja wojny (w Europie od Pierwszej Wojny Światowej, w Stanach Zjednoczonych od wojny secesyjnej), której jednym z efektów jest zacieranie rozgraniczania sfer cywilnej i wojskowej. Swoista „demokratyzacja” wojny, która zbiegała się $\mathrm{z}$ rozpowszechnianiem się zjawiska „wojen trzeciego typu”, przyniosła w efekcie zjawisko wyraźnego przesunięcia się wojny w stronę „bieguna społecznego” tradycyjnej triady, choć warto tu przypomnieć, iż te tendencje dla M. Van Crevelda oznaczają koniec wojen trynitarnych. Przesuwanie się wojny/konfliktu zbrojnego w stronę bieguna społecznego daje efekt w postaci zwiększenia ich zajadłości oraz bezwzględności. Przeniesienie znacznych obszarów konfliktu do domeny niekinetycznej (fenomen wojen hybrydowych), między innymi z uwagi na wysokie koszty polityczne „wojny kinetycznej”, pociąga za sobą rozwój środków i działań w obszarze „miękkiej” siły destrukcyjnej (soft destructive power - SDP), których celem są właśnie społeczeństwa jako konstrukty (np. niszczenie i osłabianie więzi społecznych, tradycyjnych systemów wartości, modeli społecznych; fragmentaryzacja społeczeństwa, wywoływanie wrogości wewnątrz wspólnoty itd.).Zajadłość „kinetycznych” konfliktów w społeczeństwach pierwszej i drugiej fali, opisywana jako wojny/konflikty anihilacyjne (Żurawski vel Grajewski, 2012), potwierdza obserwowane tendencje w innych „obszarach wojny” (Reginia-Zacharski, 2014). 


\section{BibLIOGRAFIA:}

Augustyniak, M. (2010). Max Weber o władzy i odpowiedzialności w polityce. Studia Prawnoustrojowe, 11.

Bagehot, W. (2016). Physics and Politics or Thoughts on the Application of the Principles of 'Natural Selection' and 'Inheritance' to Political Society. Public Domain: London.

Beck, U. (2002). The Cosmopolitan Society and its Enemies. Theory, Culture \& Society, 19(1-2).

Bell, A. (2007). The First Total War: Napoleon's Europe and the Birth of Warfare as We Know it. Boston-New York: Houghton Mifflin.

Black, J. (2010). The Age of Total War, 1860-1945. Lanham-Boulder: Rowman \& Littlefield.

Blok, Z. (2009). O polityczności, polityce i politologii. Poznań: Wyd. Naukowe WNPiD UAM.

Bueno de Mesquita, B., Smith, A., Siverson, R.M., Morrow, J.D. (2003). The Logic of Political Survival. Cambridge MA-London: Cambridge University Press.

Bueno de Mesquita, B., Siverson, R.M., Woller, G. (1992). War and the fate of regimes: A Comparative analysis. American Political Science Review, 86(3).

Bull, H. (2012). The Anarchial Society. A Study of Order in World Politics. New York: Palgrave MacMillan.

Calhoun, L. (2013). War and Delusion: A Critical Examination. New York: Palgrave MacMillan.

Cimbala, St. J. (1991). Clausewitz and Escalation: Classical Perspective on Nuclear Strategy. New York: Frank Cass.

Cimbala, St. J. (1995). U S Military Strategy and the Cold War Endgame. Ilford: Frank Cass.

Clark, G. (2017). Information Warfare: The Lost Tradecraft. Washington. D.C.: NS.

Clausewitz, C. von (2006). O wojnie. Warszawa: Mireki.

Clausewitz. C. von (2007). O naturze wojny. Warszawa: Jirafa Roha.

Crawford, V. (1991). Thomas Schelling and the analysis of strategic behaviour. W: R. J. Zeckhauser (red.). Strategy and Choice. Cambridge MA-London: MIT Press.

Creveld, M. van (2008). The Culture of War. New York: Presidio Press.

Creveld, M. van (2014). Dowodzenie na wojnie. Od Aleksandra do Szarona. Warszawa: Erica PIW.

Czajowski, J. (2011). Polityka w pięciu odsłonach: metatypologia zjawiska. Wrocławskie Studia Politologiczne, 12.

Daniluk, P. (2014). Współczesne wymiary konfrontacji informacyjnej. Rocznik Bezpieczeństwa Międzynarodowego, 8(2).

Davies, J. C. (1997). Toward a theory of revolution. W: J.C. Davies (red.). When Men Revolt and Why. New Brunswick: Transaction Publishers.

Denning, E. (2006). Wojna informacyjna i bezpieczeństwo informacji. Warszawa: WNT. 
Dinstein, Y. (1989). The distinction between unlawful combatants and war criminals. W: Y. Dinstein (red.). International Law at a Time of Perplexity. Dordrecht-Boston: Martinus Nijhoff.

Dörmann, K. (2003). The legal situation of "unlawful/unprivileged combatants. International Review of the Red Cross, 85(849).

Dz.U. 1974, nr 3, poz. 20), art. 39.

Echevarria, II A.J. (2007). Clausewitz and Contemporary War. Oxford: Oxford University Press.

Echevarria, II A.J. (2010). Preparing for One War and Getting Another? Carlisle: USAWC. Eck, K. (2005). A Beginner's Guide to Conflict Data Finding and Using the Right Dataset. Uppsala (UCDP Paper \# 1).

Edwards, J. (1986). Nuclear Weapons: The Balance of Terror, the Quest for Peace. New York: State University of New York Press.

Fearon, D. (1995). Rationalist Theories of War. International Organization, 49(3).

Fiala, S. (2010). Public War, Private Conscience: The Ethics of Political Violence. London-New York: Continuum.

Garnett, P. (2009). Przyczyny wojny i warunki pokoju. W: J. Baylis, J. Wirtz, C. S. Gray, E (red.). Strategia we współczesnym świecie. Wprowadzenie do studiów strategicznych. Cohen. Kraków: WUJ.

Giddens, J. (2003). Stanowienie społeczeństwa. Zarys teorii strukturacji. Poznań: Zysk i S-ka. Gilbert, P. (2003). New Terror, New Wars. Edinburgh: Edinburgh University Press.

Giles, K. (2016). Handbook of Russian Information Warfare. Rome: NDC.

Glaser, Ch. L. (1997). The security dilemma revisited. World Politics. 50(1).

Gruszczak, W. (2011). Hybrydowość współczesnych wojen - analiza krytyczna. W: W. Sokała, B. Zapała (red.). Asymetria i hybrydowość - stare armie wobec nowych konfliktów, Warszawa: Biuro Bezpieczeństwa Narodowego.

Hagemann, K. (2015). Revisiting Prussia's Wars against Napoleon. New York: Cambridge University Press.

Herwig, H. H. (2014). The First World War: Germany and Austria-Hungary 1914-1918, London-New York: Bloomsbury Academic.

Heuser, B. (2008). Czytając Clausewitza. Warszawa: PISM.

Hoffman, G. (2017-2018). Will War's Nature Change in the Seventh Military Revolution? Parameters, $47(4)$.

Holsti, K.J. (1992). Peace and War: Armed Conflicts and International order 1648-1989. Cambridge: Cambridge University Press.

Holsti, K.J. (2004). The State, War, and the State of War. Cambridge: Cambridge University Press.

Howard, M. (2001). Wojna $w$ dziejach Europy. Wrocław-Warszawa-Kraków: Ossolineum. Pobrane z: http://www.un.org/en/charter-united-nations/.

Information Warfare (1996). Washington. D.C.: Government Printing Office.

Jabłoński, A.W. (1991). Polityka. Interpretacje definicyjne. W: A.W. Jabłoński, L. Sobkowiak (red.). Kategorie analizy politologicznej. Wrocław: Wydawnictwo Uniwersytetu Wrocławskiego. 
Josephson, P. R. (2005). Red Atom: Russia's Nuclear Power Program from Stalin to Today. Pittsburgh: University of Pittsburgh Press.

Kagan, R. (2003). Potęga i Raj. Ameryka i Europa w nowym porzadku świata. Warszawa: Studio EMKA.

Karta Narodów Zjednoczonych (Dz.U. 1947, nr 23, poz. 90; kolejne poprawki: Dz.U. 1966, nr 7, poz. 41.

Keegan, J. (1994). A History of Warfare. London: Vintage Books.

Keegan, J. (1998). Historia wojen. Warszawa: Książka i Wiedza.

Keegan, J. (2000). A brief history of warfare - past, present, future. W: G. Prins, H. Tromp (red.). The Future of War. The Hague: The Hague.

Kranz, J. (2009). Między wojną a pokojem: świat współczesny wobec użycia siły zbrojnej. W: J. Kranz (red.). Świat wspótczesny wobec użycia sity zbrojnej. Dylematy prawa i polityki. Warszawa: IW EuroPrawo.

Krasnodębski, Z. (1999). Max Weber. Warszawa: Wiedza Powszechna.

Kuper, H. (1973). Costume and Identity. Comparative Studies in Society and History, 15(3).

Kwiecień, R. (2009). Aksjologia prawa międzynarodowego a siła zbrojna w perspektywie historycznej. W: Świat wspótczesny wobec użycia siły zbrojnej. Dylematy prawa i polityki. Warszawa: EuroPrawo.

Lawson, S. T. (2014). Nonlinear Science and Warfare: Chaos, complexity and the U.S. military in the information age. London-New York: Routledge.

Lenschow, A. (2006). Europeisation of Public Policy. W: J.J. Richardson (red.). European Union: Power and Policy-making. Abington-New York: Routledge.

Levy, S., Thompson, R. (2010). Causes of War. Malden-Oxford: Wiley-Blackwell.

Little, R. (2007). The Balance of Power in International Relations: Metaphors, Myths and Models. New York: Cambridge University.

McMahan, J. (2004). The Ethics of Killing in War. Ethics, 114.

Mumford, A. (2013). Proxy Warfare. Cambridge: Polity.

Münkler, H. (2004). Wojny naszych czasów. Kraków: Znak.

Neiberg, M. S. (2004). Warfare and Society in Europe, 1898 to the Present. London-New York: Rotledge.

Paret, P. (2007). Clausewitz and the State: The Man, His Theories, and His Times. Princeton-Oxford: Princeton University Press.

Pareto, V. (2009). The Rise and Fall of Elites: An Application of Theoretical Sociology. New Brunswick: Transaction Publishers.

Piotrowski, M. A. (2015). Konflikt nigdy nie jest prosty: amerykańska teoria i doktryna wojen oraz przeciwników hybrydowych. Sprawy Międzynarodowe, 2.

Platon (1994). Państwo. Ksiega III. Tłum. W. Witwicki. Warszawa: PWN.

Poindexter, F. (2018). The Chinese Information War: Espionage, Cyberwar, Communications Control and Related Threats to United States Interests. Jefferson: MacFarlan.

Posen, B. (1993). Security dilemma and ethnic conflict. Survival, 35(1).

Raco, M. (2015). Conflict management, democratic demands, and the post-politics of privatisation. W: J. Metzger, Ph. Allmendinger, S. Oosterlynck (red.). Planning 
Against The Political. Democratic Deficits in European Territorial Governance. New York-Abington: Routledge.

Ralph, J. (2010). War as an Institution of International Hierarchy: Carl Schmitt's Theory of the Partisan and Contemporary US Practice. Millennium: Journal of International Studies, 39(2).

Rapoport, A. (1968). Introduction. W: C. von Clausewitz, On War. London: Penguin. Rastorguyev, S. P. (1999). Informatsionnaya voina. Moskva: Radio i sv'yaz'.

Redner, H. (2017). Totalitarianism, Globalization, Colonialism: The Destruction of Civilization since 1914. London-New York: Routledge.

Reginia-Zacharski, J. (2014). Wojna $w$ świecie współczesnym. Uczestnicy, cele, modele, teorie. Łódź: Wyd. Uniwersytetu Łódzkiego.

Roberts, M. (1998). Countdown to Peace. W: G. Parker (red.). The Thirty Years' War. London-New York: Routledge.

Roland, R. (2016). War and Technology: A Very Short Introduction. New York: Oxford University Press.

Ross, E. (2015). Militarism, Pacifism and Internationalism. W: C. Marshik (red.). The Cambridge Companion to Modernist Culture. New York: Cambridge University Press.

Schelling, Th. C. (1966). Arms and Influence. Yale: Yale University.

Schelling, Th. C. (1980). The Strategy of Conflict. Cambridge, MA: Harvard University Press.

Scherrer, Ch. P. (2003). Ethnicity, Nationalism and Violence. Conflict Management, Human Rights, and Multilateral Regimes. Aldershot: Ashgate.

Schmitt, C. (1963). The Theory of the Partisan: A Commentary/Remark on the Concept of the Political. Berlin: Duncker and Humbolt.

Schoutheete, Ph. de (2001). Germany, Quo Vadis? A View from Diplomatic World. W: D. Webber (red.). New Europe, New Germany, Old Foreign Policy?: German Foreign Policy Since Unification. Abington-New York: Routledge.

Shemayev, V. (2007). Cognitive Approach to Modeling Reflexive Control in Socio-Economic Systems. Information \& Security: An International Journal, 22.

Slantchev, B. L. (2011). Military Threats. The Costs of Coercion and the Price of Peace. Cambridge-New York: Cambridge University Press.

Snyder, J. (1991). Myths of Empire: Domestic Politics and International Ambition. Ithaca. NY: Cornell University Press.

Snyder, J., Jervis, R. (1999). Civil war and the security dilemma. W: B. Walter, J. Snyder (red.). Civil Wars, Insecurity, and Intervention. New York: Columbia University Press. Sollenberg, M., Melander, E. (2017). Patterns of organized violence, 2007-16. W: SIPRI Yearbook 2017. Oxford: Oxford University Press.

Strachan, H. (2006). Training, morale and modern war, Journal of Contemporary History, $41(2)$.

Strachan, H. (2009). Carl von Clausewitz. O Wojnie. Biografia. Warszawa: Muza. 
Szafranski, R. (1997). Neocortical Warfare? The Acme of Skill. W: J. Arquilla, D. Ronfeldt (red.). In Athena's Camp: Preparing for Conflict in the Information Age. Santa Monica: RAND.

Sztumski, J. (2007). Elity - ich miejsce i rola w społeczeństwie. Katowice: Wydawnictwo Śląsk.

Tesfahuney, M., Ek, R. (2015). Planning as war by other means. W: J. Metzger, Ph. Allmendinger, S. Oosterlynck (red.). Planning Against The Political. Democratic Deficits in European Territorial Governance. New York-Abington: Routledge.

Thomas, T. L. (2004). Russia's Reflexive Control Theory and the Military. Journal of Slavic Military Studies, 17(2).

Tilly, Ch. (1975). Reflections on the History of European State Making. W: Ch. Tilly (red.). The Formation of National States in Western Europe. Princeton: Princeton University Press.

Vennesson, P. (2011). War without the People. W: H. Strachan, S. Scheipers (red.). The Changing Character of War. Oxford-New York: Oxford University Press.

Wallensteen, P. (2011). Understanding Conflict Resolution. War, Peace and the Global System. London: SAGE.

Wallensteen, P., Sollenberg, M. (2001). Armed conflict 1989-2000. Journal of Peace Research, 38(5).

Walt, St. M. (1996). Revolution and War. New York: Cornell University Press.

Walt, St. M. (2000). Rigor or Rigor Mortis? Rational Choice and Security Studies. W: M. E. Brown, O. R. Coté, Jr., S. M. Lynn-Jones, St. E. Miller (red.). Rational Choice and Security Studies: Stephen Walt and His Critics. Cambridge Mass.: MIT Press.

Walzer, M. (2010). Wojny sprawiedliwe i niesprawiedliwe. Warszawa: PWN.

Weber, M. (2002). Gospodarka i społeczeństwo. Zarys socjologii rozumiejącej. Warszawa: Wydawnictwo PWN.

Weber, M. (2011). Racjonalność, władza, odczarowanie. Poznań: Wydawnictwo Poznańskie.

Wilson, P. H. (2009). The Thirty Years War: Europe's Tragedy. Cambridge Ma.: Harvard University Press.

Wilson, P. H. (2010). The Thirty Years War: A Sourcebook. New York: Palgrave.

Wusten, van der (2005). Violence, Development, and Political Order. W: C. Flint (red.). The Geography of War and Peace: From Death Camps to Diplomats. Oxford - New York: Oxford University Press.

Zieliński, E. (2001). Nauka o państwie i polityce. Warszawa: Elipsa.

Żurawski, vel Grajewski. (2012). Bezpieczeństwo międzynarodowe. Wymiar militarny. Warszawa: Wydawnictwo PWN.

Zybertowicz, A. (1995). Przemoc i poznanie. Studium z nie-klasycznej socjologii wiedzy. Toruń: Wydawnictwo UMK.

Żyro, T. (2004). Wstęp do politologii. Warszawa: Wydawnictwo PWN. 